Aim of the study: This study aimed to observe the expressions of heat shock protein 27 (HSP27) and proliferating cell nuclear antigen (PCNA) in retinoblastoma $(\mathrm{Rb})$ cells and to explore the relationships of the expression with Rb differentiation and optic nerve infiltration. Material and methods: Heat shock protein 27 and PCNA expressions in 36 routine $\mathrm{Rb}$ paraffin specimens were observed using PV9000 two-stage immunohistochemical staining. The correlations of the HSP27 and PCNA expressions with Rb differentiation and optic nerve infiltration were analyzed.

Results: Heat shock protein 27 was weakly expressed in the normal retina, specifically in the ganglion cell layer. It was extensively expressed in $\mathrm{Rb}$ tissues at a positive rate of $69.4 \%$, and the positive substances were primarily located in the cytoplasm. Proliferating cell nuclear antigen was expressed weakly or not at all expressed in the normal retina and was extensively expressed in $\mathrm{Rb}$ tissues at a positive rate of $83.3 \%$, and the positive substances were primarily located in the nucleus. The positive expression rates of HSP27 and PCNA in the differentiated group were significantly higher than in the undifferentiated group $(p<0.05)$. The positive expression rates of HSP27 and PCNA in the optic nerveinfiltrated group were significantly higher than in the non-infiltrated group $(p<0.05)$. Heat shock protein 27 expression was positively correlated with PCNA expression in $\mathrm{Rb}(p<0.01)$.

Conclusions: Heat shock protein 27 and PCNA expressions are markedly correlated with cell differentiation and optic nerve infiltration in $\mathrm{Rb}$.

Key words: retinoblastoma, HSP27, proliferating cell nuclear antigen, immunohistochemistry.

\section{Expression of heat shock protein 27 and proliferating cell nuclear antigen in human retinoblastoma}

\author{
Dongju Qin¹, Luosheng Tan², Qinghua You', Xiangping Liư
}

1Department of Ophthalmology, Nanhui Central Hospital of Pudong New District, Shanghai, China

2Department of Ophthalmology, the Second Xiangya Hospital, Central South University, Changsha, China

\section{Introduction}

Heat shock proteins (HSPs) are found extensively in prokaryocytes and eukaryocytes. Heat shock proteins participate in protein synthesis, folding, accumulation, assembly, transportation, and degradation, functioning as molecular chaperones. Furthermore, their expressions increase under stressful conditions to protect cells from potential injuries caused by stress and cytotoxic effects, stabilize intracellular protein conformation, and prevent the occurrence of apoptosis [1-3]. According to the relative molecular weight classification, the important members of HSPs include HSP27, HSP60, HSP70, and HSP90, among others. Heat shock protein 27 is a member of the micromolecular HSP family, and its expression increases in numerous kinds of malignancies [4-6]. Furthermore, HSP27 overexpression is also closely correlated with various carcinogenic factors, such as apoptotic inhibition, enhanced cell protection, and multidrug resistance [7-9]. Overexpressed HSP27 binds to associated proteins at apoptotic accommodation points to exert a direct inhibitory effect on apoptosis. Overexpressed HSP27 also prevents the formation of apoptotic bodies either by directly isolating mitochondria-released cytochrome C or by preventing mitochondria from releasing cytochrome $C[1,2,9]$. Heat shock protein 27 is weakly expressed in normal cells but highly expressed in tumors, such as breast cancer, ovarian cancer, endometrial cancer, gastric cancer, colorectal cancer, hepatocellular cancer, bladder cancer, prostate cancer, and leukemia [10-15]. In breast cancer, ovarian cancer, gastric cancer, and prostate cancer, HSP27 overexpression is correlated with tumor infiltration, as well as chemotherapeutic and radiotherapeutic tolerance $[7,16,17]$.

Retinoblastoma $(\mathrm{Rb})$ is a common malignancy in children. In recent years, $\mathrm{Rb}$ has shown an increasing trend in incidence. The occurrence of $\mathrm{Rb}$ originates from a mutation in the $\mathrm{Rb}$ gene. Retinoblastoma poses a risk of serious vision and eye impairment, as well as life endangerment to children. However, to the best of our knowledge, no study on the correlation between HSP27 expression and $\mathrm{Rb}$ progression has been reported in the literature to date.

In the current study, the correlations of HSP27 expression in Rb cells with PCNA expression, Rb differentiation, and optic nerve infiltration were investigated. The role and pathological significance of HSP27 expression in Rb cell proliferation and migration were also explored.

\section{Material and methods}

\section{Samples}

Thirty-six post-eye enucleation $\mathrm{Rb}$ tissue specimens were investigated. The specimens were collected from the Second Xiangya Hospital of Central South University and Nanhui Central Hospital between 1999 and 2010, with 
complete records. The $\mathrm{Rb}$ children participants included 17 males and 19 females with a mean age of 2.25 years (ranging from 6 months to 8 years). All patients suffered from single eye $\mathrm{Rb}$, and did not receive radiotherapy or chemotherapy before operation. Of the $36 \mathrm{Rb}$ samples, 24 were undifferentiated (66.7\%), 12 were differentiated (33.3\%), 15 were optic nerve-infiltrated (41.8\%), and 21 were non-infiltrated (58.2\%). In addition, two normal retina specimens were used as the control. The procedure of this study was approved by the Ethics Committee of the Nanhui Central Hospital and the Second Xiangya Hospital.

\section{Immunohistochemistry}

All specimens were fixed in 10\% paraformaldehyde, routinely embedded in paraffin, serially sectioned ( $4 \mu \mathrm{m})$, and stained with hematoxylin and eosin for observation under a light microscope. The Rb specimens were divided into differentiated and non-differentiated groups according to the presence or absence of rosettes. The specimens were also divided into optic nerve-infiltrated and non-infiltrated groups according to tumor infiltration.

PV9000 two-stage staining was done. The paraffinembedded sections were dewaxed, dehydrated, and incubated with $3 \%$ peroxidase for $10 \mathrm{~min}$ at room temperature to block endogenous peroxidase activity. The sections were rinsed with distilled water and saturated in phosphate buffered saline (PBS) for $5 \mathrm{~min}$. The sections were incubated overnight at $4^{\circ} \mathrm{C}$ with a $1: 100$ dilution of mouse anti-monoclonal antibody (primary antibody; Beijing Zhongshan, China). The sections were incubated with Polymer Helper reagent for $20 \mathrm{~min}$ at $37^{\circ} \mathrm{C}$ and rinsed with PBS. Afterwards, the samples were incubated with poly peroxidase-antirabbit IgG for $20 \mathrm{~min}$ at room temperature. After PBS washing, the sections were stained with diaminobenzidine solution (Beijing Zhongshan, China), counterstained with hematoxylin, routinely dehydrated, and then mounted. Phosphate buffered saline replaced the antibodies as a negative control, and a known positive section was used as a positive control.

\section{Observation indices and result determination}

Cells with buffy-stained cytoplasms or buffy-stained nuclear particles were determined as HSP27-positive cells. PCNA-positive cells were those with specific buffy particles in the nucleus. Result determination was performed using the color morphometric image analysis system designed by the Beijing University of Aeronautics \& Astronautics, China. In this system, five high-power visual fields were randomly selected for each section under light microscopy, and a mean cell count was obtained. A positive cell count $\leq 20 \%$ was assigned a $(-)$, whereas $>20 \%$ was assigned a $(+)$.

\section{Statistical analysis}

Data were analyzed using the SPSS10.0 software. $\chi^{2}$ tests ( $2 \times 2$ table exact probability analysis), rank sum tests, and Spearman correlation analysis were performed. $P<0.05$ was considered statistically significant.

\section{Results}

\section{Clinical data}

As shown in Table 1, the patients had no history of chemotherapy.

\section{Immunohistochemical staining for HSP27 and PCNA}

Heat shock protein 27 was weakly expressed in the normal retinal nerve fiber layer (Fig. 1). In contrast, positive HSP27 was strongly expressed in 25 of $36 \mathrm{Rb}$ tissues (69.4\%), and the positive substances were primarily located in the cytoplasm and partly in the nucleus and membrane. Proliferating cell nuclear antigen was expressed weakly or not expressed in the normal retina, whereas positive PCNA was strongly expressed in $30 \mathrm{Rb}$ tissues with a positive rate of $83.3 \%$. The stained site was located in the nucleus rather than in the cytoplasm.

\section{Correlations of HSP27 and PCNA with Rb differentiation}

The positive expression rates of HSP27 and PCNA in the undifferentiated group were significantly higher than in the differentiated group ( $p<0.05$; Table 2 ). Heat shock protein 27 expressions in the Rb differentiated and undifferentiated groups are shown in Fig. 2, and the PCNA expressions in these two groups are shown in Fig. 3.

\section{Correlations of HSP27 and PCNA with Rb optic nerve infiltration}

The positive expression rates of HSP27 and PCNA in the infiltrated group were significantly higher than in the noninfiltrated group ( $p<0.05$; Table 3).

\section{Correlation between HSP27 and PCNA in $\mathrm{Rb}$ tissues}

The linear correlation analysis showed that HSP27 expression was positively correlated with PCNA expression in the $\mathrm{Rb}$ tissues $(r=0.4785, p<0.01)$.

\section{Discussion}

Heat shock proteins are groups of intracellular proteins synthesized under physiological, pathological, or stressful conditions. They bind with highly conservative amino acid sequences, as well as genes encoded by these sequences, and serve as molecular chaperones to participate in the synthesis, folding, accumulation, assembly, transportation, and degradation of proteins. Additionally, under stressful conditions, HSPs increase cellular resistance to stress injuries $[1,18]$. On one hand, increased HSP expression under stressful conditions protects cells against the potential injuries caused by stress and cytotoxicity. On the other hand, HSPs exert the functions of molecular chaperones to stabilize protein conformations in cells, thus preventing apoptosis [19]. Heat shock protein 27 is a member of the micromolecular HSP family. Under a normal state, HSP27 is weakly expressed in cells; however, once stress occurs, HSP27 expression increases, exerting an anti-oxidative damage function [20]. 
Table 1. Clinicopathological profiles in retinoblastoma cases examined in this study

\begin{tabular}{|c|c|c|c|c|c|c|c|}
\hline No. & Age & Gender & Side & Differentiation & Optic nerve invasion & HSP27 & PCNA \\
\hline 1 & 0.5 & $\mathrm{~F}$ & $\mathrm{R}$ & Un & + & + & + \\
\hline 2 & 1 & $\mathrm{~F}$ & $\mathrm{R}$ & Un & + & + & $?$ \\
\hline 3 & 0.5 & $M$ & $L$ & well & $?$ & $?$ & + \\
\hline 4 & 4 & $\mathrm{~F}$ & $\mathrm{R}$ & Un & + & + & + \\
\hline 5 & 0.5 & M & $\mathrm{R}$ & Un & $?$ & + & + \\
\hline 6 & 5 & $M$ & $L$ & Well & + & + & + \\
\hline 7 & 4 & $M$ & $\mathrm{R}$ & Un & + & + & + \\
\hline 8 & 1 & $\mathrm{~F}$ & $\mathrm{R}$ & Well & $?$ & $?$ & $?$ \\
\hline 9 & 0.5 & $\mathrm{~F}$ & $\mathrm{R}$ & Well & $?$ & + & + \\
\hline 10 & 2 & $M$ & $L$ & Un & + & $?$ & + \\
\hline 11 & 4 & $\mathrm{~F}$ & $R$ & Un & $?$ & + & + \\
\hline 12 & 0.5 & $\mathrm{~F}$ & $L$ & Well & + & $?$ & + \\
\hline 13 & 8 & $M$ & $\mathrm{R}$ & Un & + & + & + \\
\hline 14 & 3 & $\mathrm{~F}$ & $L$ & Well & $?$ & $?$ & + \\
\hline 15 & 1 & $\mathrm{~F}$ & $\mathrm{R}$ & Un & + & + & + \\
\hline 16 & 2 & $M$ & $L$ & Un & $?$ & + & + \\
\hline 17 & 3 & $\mathrm{~F}$ & $R$ & Un & $?$ & $?$ & + \\
\hline 18 & 2 & $M$ & $\mathrm{R}$ & Well & + & + & + \\
\hline 19 & 2 & $\mathrm{~F}$ & $L$ & Un & $?$ & $?$ & + \\
\hline 20 & 1 & $M$ & $R$ & Un & + & + & + \\
\hline 21 & 5 & $M$ & $L$ & Well & $?$ & + & $?$ \\
\hline 22 & 2 & $M$ & $R$ & Un & + & + & + \\
\hline 23 & 1 & $\mathrm{~F}$ & $L$ & Un & $?$ & $?$ & $?$ \\
\hline 24 & 3 & $\mathrm{~F}$ & $R$ & Well & $?$ & + & + \\
\hline 25 & 1 & $M$ & $L$ & Un & $?$ & + & $?$ \\
\hline 26 & 3 & $\mathrm{~F}$ & $R$ & Un & $?$ & + & + \\
\hline 27 & 1 & $M$ & $R$ & Un & $?$ & + & + \\
\hline 28 & 3 & $\mathrm{~F}$ & $R$ & Well & + & $?$ & $?$ \\
\hline 29 & 2 & $M$ & $L$ & Un & $?$ & + & + \\
\hline 30 & 4 & $M$ & $L$ & Un & $?$ & + & + \\
\hline 31 & 2 & $M$ & $R$ & Well & $?$ & + & + \\
\hline 32 & 1 & $\mathrm{~F}$ & $L$ & Un & + & $?$ & + \\
\hline 33 & 2 & $\mathrm{~F}$ & $L$ & Un & $?$ & + & $?$ \\
\hline 34 & 3 & $\mathrm{~F}$ & $L$ & Un & $?$ & $?$ & + \\
\hline 35 & 2 & $\mathrm{~F}$ & $L$ & Well & $?$ & + & + \\
\hline 36 & 1 & M & $R$ & Un & + & + & + \\
\hline
\end{tabular}

Un - undifferentiated, Well - well-differentiated

The correlations of HSP27 with clinical diseases, especially with tumors, have attracted increasing attention. Heat shock protein 27 is overexpressed in numerous types of tumors such as breast and ovarian cancers, which promotes tumor development. Heat shock protein 27 expression reflects the malignant potentials and prognoses of tumors [21-23]. Heat shock protein 27 overexpression is associated with tumor infiltration in breast cancer, such that HSP27 antibody treatment can increase the survival rate of patients with breast cancer [12]. Therefore, further investigation into 


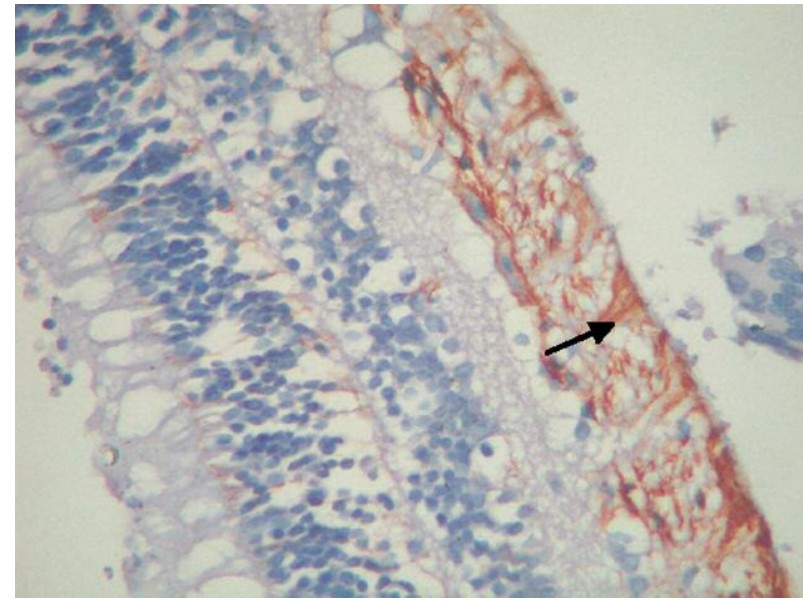

Fig. 1. HSP27 expression in the ganglion cell layer of the normal retina (DAB, magnification 200x)

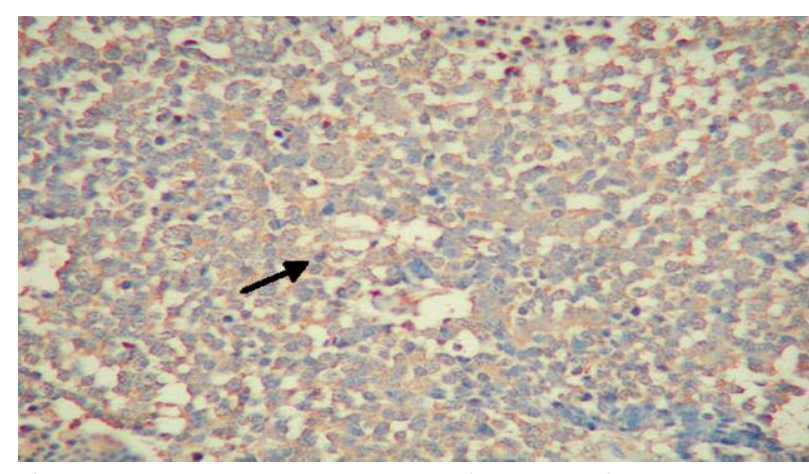

Fig. 2. HSP27 positive expression in Rb tissues: The positive particles are mainly located in cytoplasm (DAB, magnification 200x)

HSP27 expression in patients with tumors and the regulatory mechanism of HSP27 expression is of great clinical significance in the treatment of tumors.

Retinoblastoma is one of the most common malignancies in children. Increasing the early diagnosis rate and improving the cure for Rb are the keys to Rb treatment. However, although extensive studies on the biological characteristics, role, and mechanism of action of HSP27, as well as its correlations with clinical diseases, especially with tumors, have already been conducted, reports on the roles of HSP27 in the development of $\mathrm{Rb}$ are rare in the literature.

The present study shows that positive HSP27 was mainly located in the cytoplasm and extensively expressed in the $\mathrm{Rb}$ tissues. Furthermore, the positive expression rate of HSP27 was noticeably higher in the undifferentiated group than in the differentiated group $(p<0.05)$. Abnormal HSP27 expression presumably arises from DNA and/or cell injuries caused by stress, which cannot be cleared up completely. When injuries accumulate in cells to a certain level, abnormal HSP27 expression consequently leads to mutation or apoptosis. This presumption further suggests that HSP27 can play a role in the differentiation of Rb cells and promote the development of Rb. The presence of HSP27 may be an early event in the development of tumors. Heat shock protein 27 expression increases with disease progression. Thus, HSP27 expression has a certain indicative
Table 2. Relationship of the positive expression of HSP27 and PCNA with the differentiation degrees of $\mathrm{Rb}$

\begin{tabular}{lcccccc} 
Groups & $n$ & \multicolumn{2}{c}{ HSP27 } & & \multicolumn{2}{c}{ PCNA } \\
\cline { 3 - 4 } \cline { 5 - 6 } & & + & - & & + & - \\
undifferentiated & 24 & 16 & 8 & & 20 & 4 \\
differentiated & 12 & 9 & 3 & & 10 & 2 \\
$P$ & & \multicolumn{2}{c}{0.0342} & & \multicolumn{2}{c}{0.0246}
\end{tabular}

Table 3. Relationships of the positive expression of HSP27 and PCNA with nerve infiltration of $\mathrm{Rb}$

\begin{tabular}{|c|c|c|c|c|c|}
\hline \multirow[t]{2}{*}{ Groups } & \multirow[t]{2}{*}{$n$} & \multicolumn{2}{|c|}{ HSP27 } & \multicolumn{2}{|c|}{ PCNA } \\
\hline & & + & - & + & - \\
\hline$A$ & 15 & 12 & 3 & 14 & 1 \\
\hline B & 21 & 13 & 8 & 16 & 5 \\
\hline$P$ & & & & & \\
\hline
\end{tabular}

Group A - the optic nerve infiltrated group, group B - non-infiltrated group

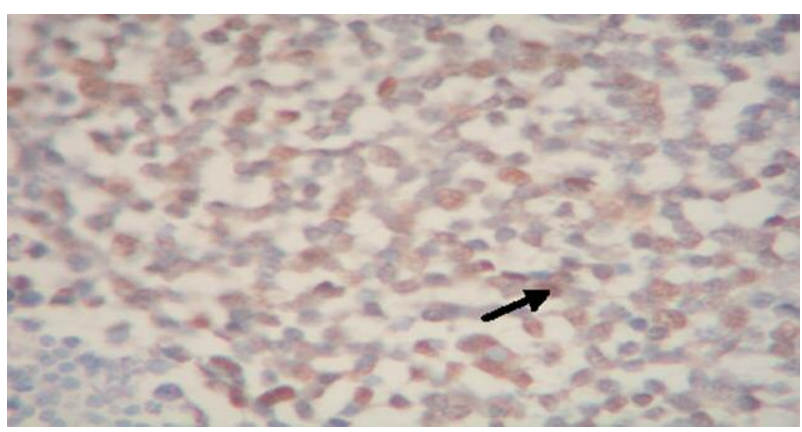

Fig. 3. PCNA positive expression in Rb tissues: The positive particles are mainly located in the nucleus (DAB, magnification 400x)

significance in determining the malignant potentials and differentiation levels of tumors [24].

In addition, evaluating cell proliferation is also of great significance in clarifying the biological characteristics of tumors. Proliferating cell nuclear antigen is a type of intranuclear polypeptide, which can only be synthesized and expressed in proliferating cells. It binds with DNA polymerase accessory proteins to participate in cellular DNA replication. Proliferating cell nuclear antigen expression is associated with the cell cycle and is primarily expressed in the $\mathrm{S}, \mathrm{G} 1$, and early $\mathrm{G} 2$ phases of a cell proliferation cycle. A previous study has indicated that PCNA is correlated with the development, differentiation, metastasis, and prognosis of tumors. Thus, PCNA expression can be used as an index for evaluating the proliferation of malignant tumor cells, as well as the malignant potential and prognosis of a tumor [25]. The correlation analysis in this study shows that PCNA expression is correlated with the differentiation and optic nerve infiltration of Rb cells. Positive PCNA was more extensively expressed in the poorly differentiated and optic nerve-infiltrated $\mathrm{Rb}$ tissues. This finding is consistent with those reported in the literature [26, 27].

Furthermore, the present study shows a positive correlation between HSP27 and PCNA expressions in Rb. The expression rates of HSP70 and HSP9O in Rb tissues are $65.12 \%$ and $86.05 \%$, respectively. HSP90 is positively correlated with Ki-67 (its expression has been used as an index for tumor cell 
proliferation evaluation), whereas HSP70 has no close correlation with $\mathrm{Ki}-67$ [28]. These findings indicate that although the HSP family is correlated with the initiation, development, differentiation, and metastasis of various malignancies, its members demonstrate different specificity to tumors located at different sites. Chemical reduction surgery can lead to high HSP27 expression in Rb. Heat shock protein 27 is closely correlated with the drug resistance of tumor cells by inhibiting their apoptosis [29]. In the present study, the results show that PCNA expression was positively correlated with HSP27 expression in Rb tissues ( $p<0.01$ ), and HSP27 was more extensively expressed in the undifferentiated and optic nerve-infiltrated Rb tissues. The reason may be that HSP27 correlates with the initiation, development, and metastasis of tumor cells by inhibiting numerous apoptotic pathways of tumor cells. Heat shock protein 27 was previously confirmed to promote the occurrence of drug resistance by regulating apoptosisassociated proteins, particularly as follows:

- it reduces the release of cytochrome $C$ and the activation of cysteine-containing aspartate-specific protease 9 by stabilizing the cytoskeleton and the translocation of apoptosis-promoting proteins toward mitochondrial membranes [30];

- HSP27 binds with and activates the serine/threonine protein kinase Akt, which deactivates the Akt substrates, such as Bad and caspase-9 (apoptosis-promoting proteins), thereby inhibiting apoptosis [31];

- it inhibits death domain-associated proteins from exerting inhibitory effects on the apoptosis of signal-regulating kinase-1 associated apoptotic pathways [32]; and

- although HSP27 has no influence on the release of cytochrome C or on the activity of Apaf-1 and caspase-9, it binds with caspase- 3 and inhibits its activity, thereby functioning as a downregulatory factor inhibiting the apoptosis of tumor cells [30, 33].

Retinoblastoma is one of the most common malignancies in children. However, although extensive studies on HSP27 have already been conducted, several issues concerning its mechanism of action in Rb still need further investigation.

The authors declare no conflict of interest.

\section{References}

1. Malusecka E, Krzyzowska-Gruca S, Gawrychowski J, Fiszer-Kierzkowska A, Kolosza Z, Krawczyk Z. Stress proteins HSP27 and HSP70i predict survival in non-small cell lung carcinoma. Anticancer Res 2008; 28: 501-6.

2. Finkel T, Serrano M, Blasco MA. The common biology of cancer and ageing. Nature 2007; 448: 767-74

3. Nakamoto $H$, Vígh L The small heat shock proteins and their clients. Cell Mol Life Sci 2007; 64: 294-306.

4. Sarto C, Binz PA, Mocarelli P. Heat shock proteins in human cancer. Electrophoresis 2000; 21: 1218-26.

5. Ciocca DR, Calderwood SK. Heat shock proteins in cancer: diag-nostic, prognostic, predictive, and treatment implications. Cell Stress Chaperones 2005; 10: 86-103.

6. Kamada M, So A, Muramaki M, Rocchi P, Beraldi E, Gleave M. Hsp27 knockdown using nucleotide-based therapies inhibit tumor growth and enhance chemotherapy in human bladder cancer cells. Cancer Ther 2007: 6: 299-308.
7. Aloy MT, Hadchity E, Bionda C, Diaz-Latoud C, Claude L, Rousson R, Arrigo AP, Rodriguez-Lafrasse C. Protective role of Hsp27 protein against gamma radiation-induced apoptosis and radiosensitization effects of Hsp27 gene silencing in different human tumor cells. Int J Radiat Oncol Biol Phys 2008; 70: 543-50.

8. Berrieman HK, Cawkwell L, O'Kane SL, Smith L, Lind MJ. Hsp27 may allow prediction of the response to single-agent vinorelbine chemotherapy in non-small cell lung cancer. Oncol Rep 2006; 15: 283-6.

9. Concannon CG, Gorman AM, Samali A. On the role of Hsp27 in regulating apoptosis. Apoptosis 2003; 8: 61-70.

10. Pei H, Zhu H, Zeng S, et al. Proteome analysis and tissue microarray for profiling protein markers associated with lymph node metastasis in colorectal cancer. J Proteome Res 2007; 6: 2495-501.

11. Zanini C, Pulerà F, Carta F, Giribaldi G, Mandili G, Maule MM, Forni M, Turrini F. Proteomic identification of heat shock protein 27 as a differentiation and prognostic marker in neuroblastoma but not in Ewing's sarcoma. Virchows Arch 2008; 452: 157-67.

12. Yu Z, Zhi J, Peng X, Zhong X, Xu A. Clinical significance of HSP27 expression in colorectal cancer. Mol Med Rep 2010; 3: 953-8.

13. Doshi BM, Hightower LE, Lee J. The role of Hsp27 and actin in the regulation of movement in human cancer cells responding to heat shock. Cell Stress Chaperones 2009; 14: 445-57.

14. Giaginis C, Daskalopoulou SS, Vgenopoulou S, Sfiniadakis I, Kouraklis G, Theocharis SE. Heat Shock Protein-27, -60 and -90 expression in gastric cancer: association with clinicopathological variables and patient survival. BMC Gastroenterol 2009; 9: 14-21.

15. Kurahashi T, Miyake H, Hara I, Fujisawa M. Expression of major heat shock proteins in prostate cancer: correlation with clinicopathological outcomes in patients undergoing radical prostatectomy. J Urol 2007; 177: 757-61.

16. Steinboeck F, Hubmann M, Bogusch A, Dorninger P, Lengheimer T, Heidenreich $E$. The relevance of oxidative stress and cytotoxic DNA lesions for spontaneous mutagenesis in non-replicating yeast cells. Mutat Res 2010; 688: 47-52.

17. King KL, Li AF, Chau GY, Chi CW, Wu CW, Huang CL, Lui WY. Prognostic significance of heat shock protein-27 expression in hepatocellular carcinoma and its relation to histologic grading and survival. Cancer 2000; 88: 2464-70.

18. Finkel T, Serrano M, Blasco MA. The common biology of cancer and ageing. Nature 2007; 448: 767-74.

19. Mosser DD, Morimoto RI. Molecular chaperones and the stress of oncogenesis. Oncogene 2004; 23: 2907-18.

20. Mese H, Sasaki A, Nakayama S, Yoshioka N, Yoshihama Y, Kishimoto K, Matsumura T. Prognostic significance of heat shock protein27 (HSP27) in patients with oral squamous cell carcinoma. Oncol Rep 2002; 9: 341-4.

21. Lemieux P, Oesterreich S, Lawrence JA, Steeg PS, Hilsenbeck SG, Harvey JM, Fuqua SA. The small heat shock protein HSP27 increases invasiveness but decreases motility of breast cancer cells. Invasion Metastasis 1997; 17: 113-23.

22. Garrido C, Fromentin A, Bonnotte B, Favre N, Moutet M, Arrigo AP, Mehlen P, Solary E. Heat shock protein 27 enhances the tumorigenicity of immunogenic rat colon carcinoma cell clones. Cancer Res 1998; 58: 5495-9.

23. Conroy SE, Sasieni PD, Amin V, Wang DY, Smith P, Fentiman IS, Latchman DS. Antibodies to heat-shock protein 27 are associated with improved survival in patients with breast cancer. Br J Cancer 1998. 77: $1875-9$

24. Arrigo AP, Firdaus WJ, Mellier G, Moulin M, Paul C, Diaz-latoud C, Kretzremy $C$. Cytotoxic effects induced by oxidative stress in cultured mammalian cells and protection provided by HSP27 expression. Methods 2005; 35: 126-38.

25. Ng IO, Lai EC, Fan ST, Ng M, Chan AS, So MK. Prognostic significance of proliferating cell nuclear antigen expression in hepatocellular carcinoma. Cancer 1994; 73: 2268-74.

26. Li DY, Song XW, Gao YE, Zhang XF. Immunohistochemical studies on proliferating cell nuclear antigen in retinoblastoma. Chin J Ophthalmology 1997; 33: 293-6.

27. Yang XJ, Zhang ZG, Zeng Q. A study of expression of p53, c-myc and PCNA in retinoblastoma. Chin J Ophthalmology 1999; 35: 252-4.

28. Jiang LB, Liu XQ, Li B, He XJ, Jin YL, Li LQ, Gao F, Wang NL. Heat shock proteins and survivin: relationship and effects on proliferation index of retinoblastoma cells. Histol Histopathol 2008; 23: 827-31. 
29. Kase S, Parikh JG, Rao NA. Expression of heat shock protein 27 and alpha-crystallins in human retinoblastoma after chemoreduction. Br J Ophthalmol 2009; 93: 541-4.

30. Paul C, Manero F, Gonin S, Kretz-Remy C, Virot S, Arrigo AP. Hsp27 as a negative regulator of cytochrome $\mathrm{C}$ release. $\mathrm{Mol}$ Cell Biol 2002; 22: 816-34.

31. Rane MJ, Pan Y, Singh S, et al. Heat shock protein 27 controls apoptosis by regulating Akt activation. J Biol Chem 2003; 278: 27828-35.

32. Charette SJ, Lavoie JN, Lambert H, Landry J. Inhibition of Daxx-mediated apoptosis by heat shock protein 27. Mol Cell Biol 2000; 20: 7602-12.

33. Zhang Y, Shen X. Heat shock protein 27 protects $L 929$ cells from cisplatin-induced apoptosis by enhancing Akt activation and abating suppression of thioredoxin reductase activity. Clin Cancer Res 2007; 13: 2855-64.

\section{Address for correspondence}

\section{Prof. Dongju Qin}

Department of Ophthalmology, Nanhui Central Hospital

of Pudong New District

No. 2800 Gongwei Road Pudong New District

201300 Shanghai, China

tel. 86-021-58022995

e-mail: djlscn@163.com

Submitted: 6.06 .2012

Accepted: 22.11 .2012 